\title{
Loss of Chromosome $Y$
}

National Cancer Institute

\section{Source}

National Cancer Institute. Loss of Chromosome Y. NCI Thesaurus. Code C36599.

A cytogenetic abnormality that refers to the loss of all or part of the sex-determining chromosome Y. It is associated with the development of the accelerated and blast phases of chronic myelogenous leukemia, BCR-ABL1 positive, and various types of carcinomas. 